\title{
Clinical Therapy in Patients with Aborted Sudden Cardiac Death due to Coronary Spasm
}

Shozo Sueda ${ }^{1}$, Tetsuji Shinohara ${ }^{2}$, Naohiko Takahashi ${ }^{2}$, Junya Shite $^{3}$, Toshihiro Shoji ${ }^{4}$, Masaharu Akao ${ }^{5}$, Yoshiyuki Kijima $^{6}$, Tohru Masuyama ${ }^{6}$, Tsuyoshi Miyaji ${ }^{7}$, Katsuhito Yamamoto ${ }^{7}$, Yoshihiro Iwasaki ${ }^{8}$, Ritsu Yoshida ${ }^{8}$, Shigeru Nakamura ${ }^{8}$, Yutaka Ogino ${ }^{9}$, Kazuo Kimura $^{9}$, Masahiro Sasai $^{10}$, Hiroshi Suzuki ${ }^{10}$, Tetsuzo Wakatsuki $^{11}$, Hiroshi Asajima ${ }^{12}$, Hiroki Teragawa ${ }^{13}$, Tetsunori Ishikawa ${ }^{14}$, Kazuo Kitamura ${ }^{14}$, Tsuyoshi Oda $^{15}$, Takashi Nakayama ${ }^{16}$, Yoshio Kobayashi ${ }^{16}$, Daiki Sunada ${ }^{17}$, Masaru Yamaki ${ }^{17}$, Fumie Nishizaki $^{18}$, Hirofumi Tomita ${ }^{18}$, Kazuo Usuda ${ }^{19}$, Hiroyuki Fujinaga ${ }^{20}$, Shoichi Kuramitsu ${ }^{21}$, Kenji Ando ${ }^{21}$, Takahiko Kiyooka $^{22}$, Kazushige Kadota ${ }^{23}$, Yoshinao Ishii ${ }^{24}$, Hayato Ohtani ${ }^{25}$, Yuichiro Maekawa ${ }^{25}$, Eiji Taguchi ${ }^{26}$, Koichi Nakao $^{26}$, Nobuaki Kobayashi ${ }^{27}$, Yoshihiko Seino ${ }^{27}$, Hitoshi Nakagawa ${ }^{28}$, Yoshihiko Saito ${ }^{28}$, Issei Komuro ${ }^{29}$, Yasuhiro Sasaki $^{30}$, Shuntaro Ikeda ${ }^{30}$, Osamu Yamaguchi ${ }^{30}$, Akiyoshi Kakutani ${ }^{31}$, Takahiro Imanaka ${ }^{32}$, Masaharu Ishihara $^{32}$, Masanobu Ishii ${ }^{33}$, Koichi Kaikita ${ }^{34}$, and Kenichi Tsujita ${ }^{34}$

\begin{abstract}
Background: Coronary artery spasm may lead to the aborted sudden cardiac death (A-SCD). Objectives: We investigated the number of coronary vasodilators, including calcium channel blocker (CCB), implantable cardioverter-defibrillator (ICD) implantation and prognosis in patients with A-SCD due to coronary spasm in the real world. Methods: We recruited 98 patients ( 82 men, mean age of $59.6 \pm 13.3$ years old) with A-SCD due to coronary spasm using a questionnaire. Results: Ventricular fibrillation (VF) as a cause of A-SCD was observed in 83 patients $(84.7 \%$ ), while pulseless electrical activity (PEA) was recognized in 12 patients (12.2\%). ICD was implanted in 58 patients and appropriate ICD therapies were recognized in 8 patients $(13.8 \%)$. There were no differences regarding medications between patients with and without ICD or between patients who survived and those who died. Mean follow-up duration was $27.1 \pm 19.9$ months and three patients died. Mortality during the follow-up period was not different patients with ICD from those without ICD. The mean number of coronary vasodilators including $\mathrm{CCB}$ in patients with spasm provocation tests under medications were significantly higher than in those without. VF as an initial cause of A-SCD was recognized in all 3 patients who died, while PEA was a final cause of death in 2 of 3 patients. Conclusions: Clinical outcomes in patients with A-SCD due to coronary spasm is satisfactory under medical and mechanical therapy. Decision of requiring the ICD implantation in patients with A-SCD due to coronary spasm is a challenging clinical problem.

KEY WORDS: aborted sudden cardiac death, calcium channel blocker, coronary vasodilator, implantable cardioverter-defibrillator, spasm provocation test under the medication
\end{abstract}

${ }^{1}$ Department of Cardiology, Ehime Prefectural Niihama Hospital, Hongou 3 choume 1-1, Niihama City, Ehime Prefecture, 792-0042, Japan, ${ }^{2}$ Department of Cardiology and Clinical Examination, Faculty of Medicine, Oita University, Japan, ${ }^{3}$ Department of Cardiology, Saiseikai Nakatsu Hospital, Japan, ${ }^{4}$ Chiba Emergency Medical Center, Japan, ${ }^{5}$ Department of Cardiology, National Hospital Organization Kyoto Medical Center, Japan, ${ }^{6}$ Hoshigaoka Medical Center, Japan, ${ }^{7}$ Kochi Health Science Center, Japan, ${ }^{8}$ Kyoto Katsura Hospital, Japan, ${ }^{9}$ Yokohama City University Medical Center, Japan, ${ }^{10}$ Showa University Fujigaoka Hospital, Japan, ${ }^{11}$ Tokushima University Hospital, Japan, ${ }^{12}$ Hakodate Central General Hospital, Japan, ${ }^{13}$ JR Hiroshima Hospital, Japan, ${ }^{14}$ Department of Cardiovascular Medicine, University of Miyazaki Hospital, Japan, ${ }^{15}$ Shimane Prefectural Central Hospital, Japan, ${ }^{16}$ Department of Cardiology, Chiba University Hospital, Japan, ${ }^{17}$ Nayoro City General Hospital, Japan, ${ }^{18}$ Department of Cardiology, Hirosaki University Graduate School of Medicine, Japan, ${ }^{19}$ Toyama Prefectural Central Hospital, Japan, ${ }^{20}$ Department of Cardiovascular Medicine, Tokushima Prefectural Central Hospital, Japan, ${ }^{21}$ Department of Cardiology, Kokura Memorial Hospital, Japan, ${ }^{22}$ Tokai University Oiso Hospital, Japan, ${ }^{23}$ Kurashiki Central Hospital, Japan, ${ }^{24}$ Asahikawa City Hospital, Japan, ${ }^{25}$ Hamamatsu University School of Medicine Internal Medicine III, Japan, ${ }^{26}$ Saiseikai Kumamoto Hospital, Japan, ${ }^{27}$ Nippon Medical School Chiba Hokusou Hospital, Japan, ${ }^{28}$ Nara Medical University, Japan, ${ }^{29}$ Department of Cardiovascular Medicine, The University of Tokyo Hospital, Japan, ${ }^{30}$ Ehime University Hospital, Japan, ${ }^{31}$ Yoshinogawa Medical Center, Japan, ${ }^{32}$ Hyogo College of Medicine, Japan, ${ }^{33}$ Department of Cardiology, Miyazaki Prefectural Nobeoka Hospital, Japan, ${ }^{34}$ Department of Cardiovascular Medicine, Graduate School of Medical Sciences, Kumamoto University, Japan

E-mail: EZF03146@nifty.com

Received: September 17, 2020; Accepted: November 17, 2020

doi: 10.7793/jcad.26.20-00025 


\section{Introduction}

Medical and mechanical therapy in patients with aborted sudden cardiac death (A-SCD) due to coronary spasm is controversial in the clinic $^{1-4)}$. Medication, including calcium channel blocker (CCB) and other vasodilators, is the first line therapy, while an implantable cardioverter-defibrillator (ICD) is defined as class IIa when patients have resistant coronary spasm according to the 2018 Japanese Circulation Society (JCS)/Japanese Heart Rhythm Society guideline on non-pharmacotherapy of cardiac arrhythmias $^{5)}$. JCS guideline for the diagnosis and treatment of patients with vasospastic angina (VSA) mentioned that ICD implantation is one option for patients with A-SCD due to coronary spasm ${ }^{6}$. We previously reported that appropriate ICD therapies rescued 30 out of 33 patients with A-SCD due to coronary spasm, whereas 3 patients died: 2 due to PEA and 1 due to refractory coronary spasm ${ }^{7}$. ICD was effective in patients with A-SCD due to coronary spasm to suppress the next serious fatal events $^{8,9)}$. In contrast, aggressive medications, including over two CCBs or more than 3 coronary vasodilators, were administered in just one-third of patients with A-SCD due to coronary spasm according to the previous report. ICD may not be always necessary for all patients with A-SCD due to coronary spasm. However, cardiologists have no answer for which A-SCD patients must receive ICD to suppress the next fatal events. Furthermore, cardiologists have no answer about the optimal medication to suppress the next fatal serious events.

In this article, we investigated the use of medications and ICD in patients with A-SCD due to coronary spasm. We also compared the prognosis and medication in patients with and without ICD. Furthermore, we investigated the usefulness of spasm provocation tests under the medications in A-SCD patients with coronary spasm.

\section{Methods}

We sent a questionnaire about patients with A-SCD due to coronary spasm at Mar 2019. This questionnaire was distributed among Japanese general institutions over 400-500 beds at random in 204 cardiology institutions including 101 hospitals in West Japan and 103 institutions in East Japan. The answer deadline for the questionnaire was Jun 2019. We investigated the number of SCDs due to coronary spasm, implantation of ICDs, and all spasm provocation tests, including the pharmacological spasm provocation tests under the medications, from Jan 2014 to Dec 2018 (Supplementary files 1-5).

The study protocol complied with the Declaration of Helsinki. Written informed consent was obtained before performing the pharmacological spasm provocation tests, and the protocol of this study was in agreement with the guidelines of the ethical committee at our institution and institutional review boards of their institutions.

\section{The definition of VSA and positive spasm and ischemic ECG changes}

According to the JCS guidelines ${ }^{6}$, definite VSA was defined when myocardial ischemia or coronary spasm was obtained in examinations. Spontaneous coronary spasm or provoked positive spasm by pharmacological spasm provocation tests was defined as $\geq 90 \%$ transient narrowing with ischemic findings. The degree of ST-segment depression was measured $80 \mathrm{msec}$ after the $\mathrm{J}$ point. We considered a result to be positive when at least 1 of the following ischemic ECG changes was demonstrated during spontaneous spasm or pharmacological spasm provocation test: (1) ST-segment elevation of $\geq 0.1 \mathrm{mV}$ in at least 2 contiguous leads ; (2) ST-segment depression of $0.1 \mathrm{mV}$ in at least two contiguous leads.

\section{Statistical analysis}

Data analysis was carried out with SPSS (version 22.0, IBM Japan, Ltd., Tokyo, Japan). All data were presented as the mean \pm SD. Clinical characteristics were analyzed by the Fisher's exact test with correction or the Mann-Whitney U test. Univariate analyses were performed by Cox regression proportional hazards adjusted by age, gender, number of coronary vasodilators or calcium channel blockers, multivessel spasm, spontaneous spasm, ICD implantation and positive spasm provocation test under medications. Event-free survival curves from death were constructed using the Kaplan-Meier survival method. In all analyses, $\mathrm{p}<0.05$ was regarded as statistically significant.

\section{Results}

\section{Collection rate}

The percentage of reply for questionnaires was $16.7 \%$ $(34 / 204)$. The response rate of questionnaire in East Japan was $13.6 \%(14 / 103)$, while the questionnaire collection rate in West Japan was $19.8 \%$ (20/101). Seven institutions (3.4\%) answered that they could not obtain the questionnaire result due to busy daily works or strict ethics committees in their hospitals. The remaining 163 institutions (79.9\%) had no answers.

\section{Clinical characteristics in patients with A-SCD due to coronary spasm}

We recruited 169 patients with A-SCD due to possible coronary spasm as shown in Fig. 1. However, a couple of institutions did not provide the precise data for 39 patients. Furthermore, 32 patients including 27 patients with suspected of VSA and 5 patients enrolled before Jan 2014 were excluded from our study subjects. Finally, as shown in Table 1, we recruited 98 patients 
(mean age: $59.6 \pm 13.3$ years old, male: $83.7 \%$ ) with A-SCD due to coronary spasm. Mean number of A-SCD per institution was $3.8 \pm 3.8$ patients. Organic stenosis was found in 7 patients (7.1\%). Ventricular fibrillation (VF) was observed in 83 patients (84.7\%), while pulseless electrical activity (PEA) was recognized in 12 patients (12.2\%). One patient had unknown cause of A-SCD, while ventricular tachycardia was found in one patient. Complete atrioventricular block was recognized in one patient. Approximately three quarters patients (73 patients (74.5\%)) had provoked spasm by pharmacological spasm provocation tests, while spontaneous coronary spasm was documented in 12 patients $(12.2 \%)$ and 10 patients $(10.2 \%)$ showed spontaneous ST elevation. A-SCD was documented in $3(3.1 \%)$ definite VSA patients under medication. ICD was implanted in 58 patients (59.2\%), including 5 patients complicated with Brugada syndrome and 2 patients with early repolarization syndrome. The mean follow-up period was $27.1 \pm 19.9$ months. During the follow-up periods, appropriate ICD therapies were recognized in 8 (13.8\%) patients, including 5 VFs and 3 ventricular tachycardias.

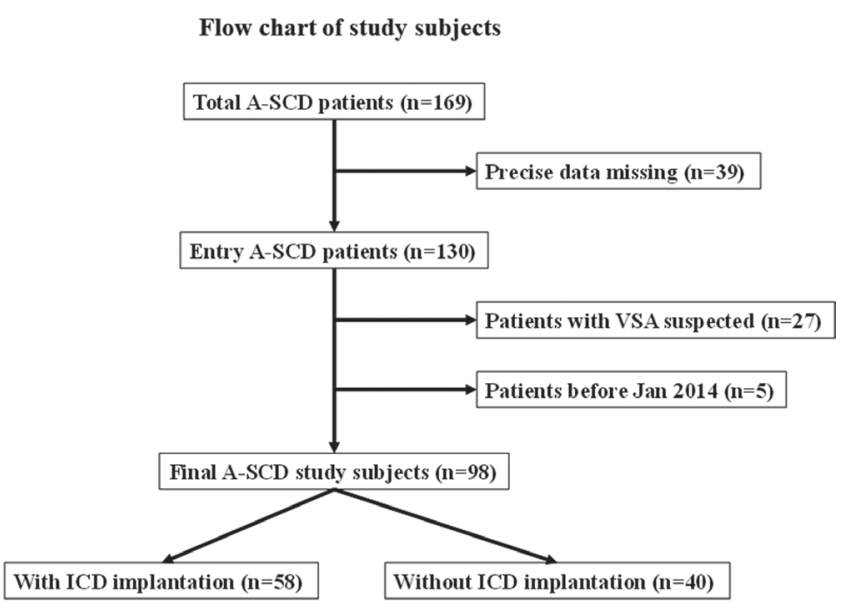

Fig. 1 Flow chart of study subjects.

A-SCD: aborted sudden cardiac death, VSA: vasospastic angina, ICD: implantable cardioverter-defibrillator

Table 1 Patients' clinical characteristics of aborted sudden cardiac death due to coronary spasm

\begin{tabular}{|c|c|}
\hline Number & 98 \\
\hline Age (year) & $59.6 \pm 13.3$ \\
\hline Male & $82(83.7 \%)$ \\
\hline Organic stenosis $(>75 \%)$ & $7(7.1 \%)$ \\
\hline Follow-up duration (month) & $27.1 \pm 19.9$ \\
\hline \multicolumn{2}{|l|}{ Cause of aborted SCD } \\
\hline Ventricular fibrillation & $83(84.7 \%)$ \\
\hline Ventricular tachycardia & $1(1.0 \%)$ \\
\hline Pulseless electrical activity & $12(12.2 \%)$ \\
\hline Complete atrioventricular block & $1(1.0 \%)$ \\
\hline Unknown & $1(1.0 \%)$ \\
\hline \multicolumn{2}{|l|}{ Diagnosis of spasm } \\
\hline $\begin{array}{l}\text { Provoked spasm by the pharmacological } \\
\text { spasm provocation test }\end{array}$ & $73(74.5 \%)$ \\
\hline Spontaneous spasm documented & $12(12.2 \%)$ \\
\hline Spontaneous ST elevation documented & $10(10.2 \%)$ \\
\hline VSA definite & $3(3.1 \%)$ \\
\hline With ICD implantation & $58(59.2 \%)$ \\
\hline Without ICD implantation & $40(40.8 \%)$ \\
\hline $\begin{array}{l}\text { With Brugada syndrome or early repolarization } \\
\text { syndrome }\end{array}$ & $7(7.1 \%)$ \\
\hline Appropriate ICD shocks & $8(13.8 \%)$ \\
\hline Mean number of coronary vasodilators & $2.2 \pm 1.0$ \\
\hline Mean number of calcium channel blockers & $1.3 \pm 0.5$ \\
\hline Death & $3(3.0 \%)$ \\
\hline With ICD implantation & $2(2.0 \%)$ \\
\hline Without ICD implantation & $1(1.0 \%)$ \\
\hline
\end{tabular}


Table 2 Comparisons of clinical data between patients with and without ICD implantation

\begin{tabular}{|c|c|c|c|}
\hline & $\begin{array}{l}\text { With ICD } \\
\text { implantation }\end{array}$ & $\begin{array}{l}\text { Without ICD } \\
\text { implantation }\end{array}$ & $\mathrm{p}$ value \\
\hline Number & 58 & 40 & \\
\hline Age (year) & $57.5 \pm 13.0$ & $62.7 \pm 13.3$ & 0.0439 \\
\hline Male & $50(86.2 \%)$ & $32(80.0 \%)$ & 0.4464 \\
\hline Organic stenosis $(>75 \%)$ & $5(8.6 \%)$ & $2(5.0 \%)$ & 0.4743 \\
\hline Follow-up duration (month) & $29.3 \pm 21.1$ & $23.3 \pm 17.4$ & 0.1493 \\
\hline \multicolumn{4}{|l|}{ Cause of aborted SCD } \\
\hline Ventricular fibrillation & $53(91.4 \%)$ & $30(75.0 \%)$ & 0.0509 \\
\hline Ventricular tachycardia & $1(1.7 \%)$ & 0 & 0.8609 \\
\hline Pulseless electrical activity & $2(3.4 \%)$ & $10(25.0 \%)$ & 0.0019 \\
\hline Complete atrioventricular block & $1(1.7 \%)$ & 0 & 0.8609 \\
\hline Unknown & $1(1.7 \%)$ & 0 & 0.8609 \\
\hline \multicolumn{4}{|l|}{ Diagnosis of spasm } \\
\hline $\begin{array}{l}\text { Provoked spasm by the pharmacological spasm } \\
\text { provocation test }\end{array}$ & $44(75.9 \%)$ & $29(72.5 \%)$ & 0.7614 \\
\hline Spontaneous spasm documented & $6(10.3 \%)$ & $6(15.0 \%)$ & 0.7402 \\
\hline Spontaneous ST elevation documented & $7(12.1 \%)$ & $3(7.5 \%)$ & 0.6640 \\
\hline VSA definite & $1(1.7 \%)$ & $2(5.0 \%)$ & 0.7591 \\
\hline With Brugada or early repolarization & $7(12.1 \%)$ & 0 & 0.0561 \\
\hline Mean number of coronary vasodilators & $2.1 \pm 1.0$ & $2.3 \pm 1.0$ & 0.4614 \\
\hline Mean number of calcium channel blockers & $1.3 \pm 0.6$ & $1.3 \pm 0.6$ & 0.8898 \\
\hline Death & $2(3.4 \%)$ & $1(2.5 \%)$ & 0.7591 \\
\hline
\end{tabular}

(SCD: sudden cardiac death, VSA: vasospastic angina, ICD: implantable cardioverter-defibrillator)

The mean numbers of coronary vasodilators and CCBs at the baseline were $2.2 \pm 1.0$ and $1.3 \pm 0.5$, respectively. During the follow-up periods, death was observed in two patients with ICD, while one patient without ICD died.

\section{Comparisons between patients with and without ICD}

As shown in Table 2, patients with ICD were younger than those without ICD. The frequency of VF in patients with ICD implantation was higher than in those without ICD but not significant, while the incidence of PEA in patients without ICD was significantly higher than in those with ICD (25.0\% vs. $3.4 \%$, $\mathrm{p}=0.0019)$. There were no differences regarding medications, including coronary vasodilators and $\mathrm{CCBs}$, between the two groups. Mortality rate during the follow-up periods in patients with ICD was not different from that in those without ICD $(3.4 \%$ vs. $2.5 \%, \mathrm{p}=0.7591)$. Death-free survival in all patients with A-SCD who had ICD was not different from those without ICD, as shown in Fig. 2a. As shown in Fig. 2b, death-free survival in patients with A-SCD due to pure coronary spasm who had ICD implantation was similar to that in patients without ICD.

\section{Comparisons of clinical data between patients who survived or who died}

Death was observed in 3 patients, while the 95 patients remained alive during the follow-up periods. Patients who died were older than those who survived $(68.7 \pm 6.8$ vs. $59.3 \pm 13.4$ year old, $\mathrm{p}=0.0276$ ). VF as a cause of A-SCD in patients who survived was not different from that in those who died $(84.2 \%$ vs. $100 \%, \mathrm{p}=0.9807)$. Furthermore, there were no differences regarding medications, including mean number of coronary vasodilators and CCBs, between the two groups.

\section{Comparisons of clinical data between patients with and without Brugada and early repolarization syndrome}

There is no difference except mean number of CCB between the two groups. Mean number of CCB in patients with Brugada and early repolarization syndrome was markedly lower than those in patients without it $(0.9 \pm 0.4$ vs. $1.3 \pm 0.5, \mathrm{p}=0.0136)$.

\section{Comparison of clinical data between patients with and without appropriate ICD therapies}

Appropriate ICD therapies were observed in 8 patients. There were no differences between the two groups. No death was observed in patients with appropriate ICD therapies, whereas two 


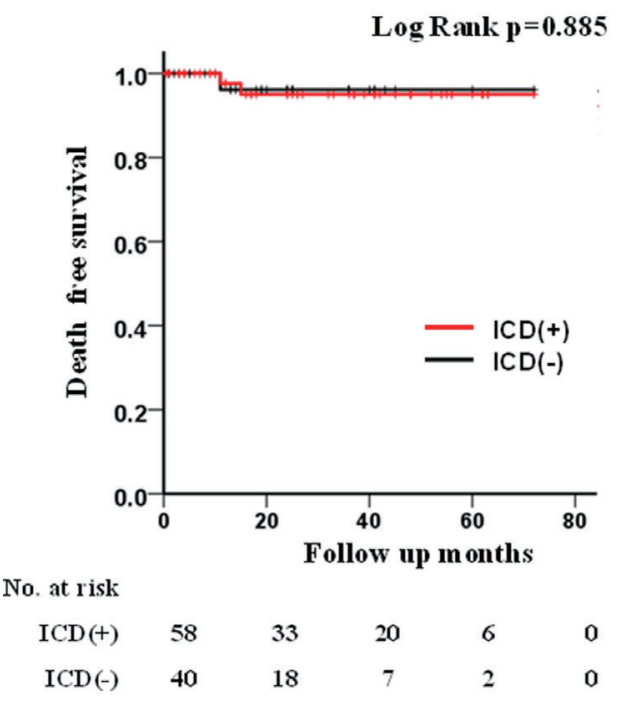

(a)

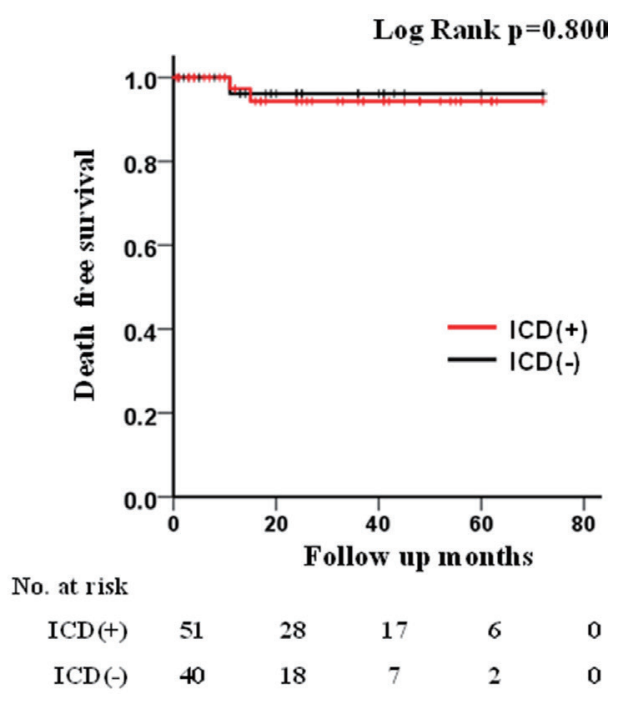

(b)

Fig. 2 Kaplan-Meier survival curve in patients with A-SCD due to coronary spasm. a: with Brugada syndrome and early repolarization syndrome. b: without Brugada syndrome and early repolarization syndrome.

Table 3 Spasm provocation data in patients with aborted sudden cardiac death due to coronary spasm

\begin{tabular}{|c|c|c|c|c|c|c|c|c|c|c|}
\hline & $\mathrm{ACh}$ & ER & $\begin{array}{c}\text { RCA } \\
\text { positive }\end{array}$ & $\begin{array}{c}\mathrm{LCX} \\
\text { positive }\end{array}$ & $\begin{array}{l}\text { LAD } \\
\text { positive }\end{array}$ & $\begin{array}{c}\text { LMT } \\
\text { positive }\end{array}$ & $\begin{array}{l}1 \text { vessel } \\
\text { spasm }\end{array}$ & $\begin{array}{l}2 \text { vessel } \\
\text { spasm }\end{array}$ & $\begin{array}{l}3 \text { vessel } \\
\text { spasm }\end{array}$ & $\begin{array}{l}\text { Multiple } \\
\text { spasm }\end{array}$ \\
\hline $\begin{array}{l}\text { With ICD } \\
\text { implantation } \\
(\mathrm{n}=44)\end{array}$ & 39 & 7 & $\begin{array}{c}23 \\
(52.3 \%)\end{array}$ & $\begin{array}{c}15 \\
(34.1 \%)\end{array}$ & $\begin{array}{c}33 \\
(75.0 \%)\end{array}$ & $\begin{array}{c}3 \\
(6.8 \%)\end{array}$ & $\begin{array}{c}17 \\
(38.6 \%)\end{array}$ & $\begin{array}{c}19 \\
(43.2 \%)\end{array}$ & $\begin{array}{c}8 \\
(18.2 \%)\end{array}$ & $\begin{array}{c}27 \\
(61.4 \%)\end{array}$ \\
\hline $\begin{array}{l}\text { Without ICD } \\
\text { implantation } \\
(\mathrm{n}=29)\end{array}$ & 19 & 8 & $\begin{array}{c}20 \\
(69.0 \%)\end{array}$ & $\begin{array}{c}9 \\
(31.0 \%)\end{array}$ & $\begin{array}{c}16 \\
(55.2 \%)\end{array}$ & $\begin{array}{c}0 \\
(0 \%)\end{array}$ & $\begin{array}{c}15 \\
(51.7 \%)\end{array}$ & $\begin{array}{c}10 \\
(34.5 \%)\end{array}$ & $\begin{array}{c}4 \\
(13.8 \%)\end{array}$ & $\begin{array}{c}14 \\
(48.3 \%)\end{array}$ \\
\hline $\mathrm{P}$ value & & & 0.1560 & 0.7856 & 0.0776 & 0.4045 & 0.2701 & 0.4573 & 0.6205 & 0.2701 \\
\hline $\begin{array}{l}\text { TOTAL } \\
(\mathrm{n}=73)\end{array}$ & 58 & 15 & $\begin{array}{c}43 \\
(58.9 \%)\end{array}$ & $\begin{array}{c}24 \\
(32.9 \%)\end{array}$ & $\begin{array}{c}49 \\
(67.1 \%)\end{array}$ & $\begin{array}{c}3 \\
(4.1 \%)\end{array}$ & $\begin{array}{c}32 \\
(43.8 \%)\end{array}$ & $\begin{array}{c}29 \\
(39.7 \%)\end{array}$ & $\begin{array}{c}12 \\
(16.4 \%)\end{array}$ & $\begin{array}{c}41 \\
(56.2 \%)\end{array}$ \\
\hline
\end{tabular}

(ACh: acetylcholine, ER: ergonovine, RCA: right coronary artery, LCX: left circumflex artery, LAD: left anterior descending artery, ICD: implantable cardioverter-defibrillator)

patients without appropriate ICD therapies died due to PEA.

\section{Spasm provocation data}

During the 5 years, pharmacological spasm provocation tests were performed in 5,027 examinations in 34 institutions. Table 3 shows the spasm provocation results in patients with A-SCD due to coronary spasm. There was no difference regarding the incidence of provoked positive spasm between patients with and without ICD. Left main trunk spasm was observed in 3 patients with ICD implantation, while patients without ICD implantations had no left main trunk spasm.

\section{Clinical findings in patients who had spasm provocation tests under medications}

As shown in Table 4, spasm provocation tests under the medications were performed in 18 (18.4\%) out of 98 patients. Provoked positive spasm recognized before medications were attenuated or disappeared in 7 patients after the tests under medications. However, provoked spasm was not attenuated in 11 patients irrespective of performing the spasm provocation tests under medications. The mean number of coronary vasodilator in patients with spasm provocation tests under medications was significantly higher than in those without $(3.0 \pm 1.1$ vs. $2.0 \pm 0.9$, $\mathrm{p}=0.0036$ ). The mean number of CCBs in patients with spasm provocation tests under medication was also remarkably higher than in those without it $(1.8 \pm 0.5$ vs. $1.2 \pm 0.5, \mathrm{p}=0.0010)$. During the follow-up periods, there were no death in all 18 patients with spasm provocation tests under medications, while appropriate ICD therapies were observed in 3 out of 8 patients with ICD. Two ventricular tachycardias and one ventricular fibrillation were recovered after the appropriate ICD therapies.

\section{Clinical and angiographic findings in patients who died}

As shown in Table 5, 3 patients died within 2 years after A-SCD. Three coronary vasodilators were administered in one patient, while one case had two CCBs. Although VF was recog- 
Table 4 Clinical findings and spasm provocation tests without medication and under medication in 18 patients with aborted sudden cardiac death due to coronary spasm

\begin{tabular}{|c|c|c|c|c|c|c|c|c|c|}
\hline No & Age & Sex & Cause & ICD & $\begin{array}{l}\text { Spontaneous spasm } \\
\text { or ST change }\end{array}$ & $\begin{array}{l}\text { Spasm provocation test } \\
\text { without medication }\end{array}$ & $\begin{array}{l}\text { Spasm provocation test under } \\
\text { medications }\end{array}$ & $\begin{array}{l}\text { Number of } \\
\text { coronary } \\
\text { vasodilators }\end{array}$ & $\begin{array}{l}\text { Number of } \\
\text { CCB }\end{array}$ \\
\hline 1 & 66 & $\mathrm{M}$ & $\mathrm{VF}$ & no & & $\mathrm{ER}(\mathrm{R}: 20 / \mathrm{L}: 32) \# 2(\mathrm{~d}) \# 13(\mathrm{~d})$ & ER(R: 20/L: 32) no spasm & 2 & 2 \\
\hline 2 & 49 & $\mathrm{~F}$ & $\mathrm{CAVb}$ & yes & ST ele in INF & Not implemented & $\begin{array}{l}\text { ACh(L: 20/50/100/200) \#7(f) } \\
\# 11(d)\end{array}$ & 3 & 2 \\
\hline 3 & 52 & M & VF & yes & & $\begin{array}{l}\text { ACh(R: 20/L: 20) \#4(d) \#5(f) } \\
\# 7(f)\end{array}$ & $\begin{array}{l}\text { ACh after ER(R: 80/L: 200) } \\
\# 7 \text { (f) }\end{array}$ & 3 & 2 \\
\hline 4 & 68 & M & VF & no & ST ele in ANT & $\begin{array}{l}\text { ACh(R: 50/L: 20) \#3(t) \#6(t) } \\
\# 11(\mathrm{~d})\end{array}$ & $\begin{array}{l}\text { ACh after ER(R: 80/L: 200) } \\
\# 3 \text { (f) }\end{array}$ & 3 & 2 \\
\hline 5 & 73 & M & VF & no & Negative $\mathrm{T}$ in ANT & $\begin{array}{l}\mathrm{ACh}(\mathrm{R}: 25 / \mathrm{L}: 25) \quad \# 2(\mathrm{t}) \# 7(\mathrm{~d}) \\
\# 11(\mathrm{~d})\end{array}$ & $\begin{array}{l}\text { ACh(R: 25/L: 25/50/100) } \\
\# 2(\mathrm{f}) \# 8(\mathrm{f}) \# 13(\mathrm{~d})\end{array}$ & 3 & 2 \\
\hline 6 & 69 & M & VF & yes & & $\begin{array}{l}\text { ACh(R: 20/L20/50/100) \#2(t) } \\
\# 7 \text { (subt) \#13(d) }\end{array}$ & $\begin{array}{l}\mathrm{ACh}(\mathrm{R}: 20 / \mathrm{L}: 20 / 50 / 100) \\
\# 2(\mathrm{t}) \# 7(\mathrm{f}) \# 13(\mathrm{~d})\end{array}$ & 2 & 1 \\
\hline 7 & 64 & M & VF & yes & & $\begin{array}{l}\text { ACh(R: 20/50/L: 20/50) } \\
\# 1 / 4(\mathrm{~d}) \# 8 / 9 / / 11 / 12(\mathrm{~d})\end{array}$ & $\begin{array}{l}\mathrm{ACh}(\mathrm{R}: 20 / 50 / \mathrm{L} ; 20 / 50) \\
\# 1 / 4 \text { (d) } \# 8 / 9 / 11 / 12 \text { (d) }\end{array}$ & 4 & 2 \\
\hline 8 & 42 & M & VF & yes & & $\begin{array}{l}\text { ER(R: 20/40/L: 40/80) } \\
\# 2 / 3(d) \# 6(d)\end{array}$ & $\begin{array}{l}\text { ER(R: 10/20/30/L: 10/20) } \\
\# 7(\mathrm{~d})\end{array}$ & 4 & 2 \\
\hline 9 & 82 & $\mathrm{~F}$ & VF & yes & & $\begin{array}{l}\text { ER(R: 20/50/L: 20/50/100) } \\
\# 7(f)\end{array}$ & $\begin{array}{l}\text { ER(R: 20/30/L: 30/30) no } \\
\text { spasm }\end{array}$ & 5 & 3 \\
\hline 10 & 45 & M & VF & no & & $\begin{array}{l}\mathrm{ACh}(\mathrm{R}: 20 / 50 / \mathrm{L}: 20 / 50 / 100) \\
\# 4(\mathrm{~d}) \# 7(\mathrm{~d})\end{array}$ & $\begin{array}{l}\mathrm{ACh}(\mathrm{R}: 20 / 50 / \mathrm{L}: 20 / 50 / 100) \\
\# 4(\mathrm{~d}) \# 7(\mathrm{~d})\end{array}$ & 1 & 1 \\
\hline 11 & 38 & $\mathrm{~F}$ & VF & yes & & $\begin{array}{l}\text { ACh(R: 20/50/L: 20/50/100) } \\
\# 4(d) \# 7(\mathrm{~d})\end{array}$ & $\begin{array}{l}\text { ACh(R: 20/50/L: 20/50/100) } \\
\# 4(d) \# 7 \text { (d) }\end{array}$ & 1 & 1 \\
\hline 12 & 25 & M & $\mathrm{VF}$ & yes & & $\begin{array}{l}\operatorname{ACh}(\mathrm{R}: 20 / 50 / \mathrm{L}: 20 / 50 / 100) \\
\# 4 \operatorname{AV}(\mathrm{d}) \# 8(\mathrm{~d})\end{array}$ & $\begin{array}{l}\text { ACh(R: 20/50/L: 20/50/100) } \\
\# 4 A V(d) \# 8(d)\end{array}$ & 2 & 1 \\
\hline 13 & 69 & $\mathrm{~F}$ & VF & no & & $\begin{array}{l}\mathrm{ACh}(\mathrm{R}: 20 / 50) \# 2 \text { (subt) } \\
\# 4 \mathrm{PD} \text { (subt) }\end{array}$ & $\begin{array}{l}\text { ACh(R: 20/50) \#2(subt) } \\
\# 4 \text { (subt) }\end{array}$ & 2 & 1 \\
\hline 14 & 69 & $\mathrm{~F}$ & VF & no & & $\mathrm{R}(20 / 50 / 100) \quad \# 4 \mathrm{PD}$ (subt) & $\mathrm{R}(20 / 50 / 100) \quad \# 4 \mathrm{PD}($ subt $)$ & 4 & 2 \\
\hline 15 & 64 & M & VF & no & & $\begin{array}{l}\text { ACh(R: } 20 / 50 / 100 / \\
\text { L: } 20 / 50 / 100) \# 1(\mathrm{t})\end{array}$ & $\begin{array}{l}\text { ACh(R: } 20 / 50 / 100 / \\
\text { L: } 20 / 50 / 100) \# 1(\mathrm{t})\end{array}$ & 4 & 2 \\
\hline 16 & 64 & M & VF & no & $\# 1$ (subt) spasm & Not implemented & $\begin{array}{l}\text { ACh(R: 20/50/L: 20/50/100) } \\
\text { no spasm }\end{array}$ & 3 & 2 \\
\hline 17 & 67 & M & VF & no & $\# 1 / 6 / 11$ (f) spasm & Not implemented & $\operatorname{ACh}(\mathrm{L}: 20 / 50 / 100) \# 13(\mathrm{~d})$ & 4 & 2 \\
\hline 18 & 57 & M & VF & no & VSA definite & Not implemented & $\operatorname{ACh}(\mathrm{L}: 20 / 50) \# 7(\mathrm{~d}) \# 14(\mathrm{~d})$ & 4 & 2 \\
\hline Mean & 59 & & & (8) & & & & $3.0 \pm 1.1$ & $1.8 \pm 0.5$ \\
\hline
\end{tabular}

(ICD: implantable cardioverter-defibrillator, $\mathrm{CCB}$ : calcium channel blocker, M: male, F: female, VF: ventricular fibrillation, CAVb: complete atrio-ventricular block, INF: inferior, ANT: anterior, VSA: vasospastic angina, (f): focal spasm (subt): subtotal, (d): diffuse spasm, (t): total, ACh: acetylcholine, ER: ergonovine, R: right coronary artery, L: left coronary artery)

nized in all 3 patients as an initial diagnosis, no final cause of VF was found. PEA was observed in 2 patients as a final cause of death.

\section{Univariate Cox hazard regression analyses for death}

No determinant factors for death-free survival was found.

\section{Discussion}

In this article, we showed the satisfactory clinical outcomes in patients with A-SCD due to coronary spasm under medical and mechanical therapies. However, appropriate ICD therapy was recognized in just $8(13.8 \%)$ patients, including $5 \mathrm{VFs}$ and 3 ventricular tachycardias, whereas the remaining $86.2 \%$ of patients had no appropriate ICD therapy. There were no differences regarding the number of coronary vasodilators or CCBs between patients with and without ICD or between patients who survived and those who died. The mean number of coronary vasodilators or CCBs in patients with spasm provocation tests under medica- tions was significantly higher than the number without tests. No deaths during the follow-up period were recognized in patients with spasm provocation tests under medications. Death due to PEA was observed in 2 patients with ICD implantation, although VF was the initial cause of A-SCD in all 3 died patients. Cardiologists should reconsider the medications administered in patients with A-SCD due to coronary spasm. Furthermore, cardiologists should select patients with A-SCD who require ICD to suppress the next fatal events due to pure coronary spasm.

\section{Coronary vasodilators and CCBs}

According to previous data in patients with A-SCD due to coronary spasm, the mean coronary vasodilator numbers were $2.6 \pm 0.9$ (Ahn et al) ${ }^{10)}, 1.5 \pm 0.7$ (Manero et al) ${ }^{11)}$, or $2.0 \pm 0.8$ (Sueda et $\mathrm{al})^{7)}$. In this study, the mean number of coronary vasodilators was $2.2 \pm 1.0$, and the mean number of CCBs was $1.3 \pm 0.5$. The mean number of coronary vasodilators in this study was similar to that in VSA patients without A-SCD in the study by 
Journal of Coronary Artery Disease 2020; 26: 91-99

Table 5 Clinical and angiographic findings in patients with death who survived from aborted sudden cardiac death once time

\begin{tabular}{|c|c|c|c|c|c|c|c|c|c|c|}
\hline No & Age & Sex & $\begin{array}{c}\text { Initial } \\
\text { diagnosis }\end{array}$ & $\begin{array}{l}\text { Organic } \\
\text { stenosis }\end{array}$ & ICD & $\begin{array}{c}\text { Spasm provocation test or } \\
\text { spontaneous spasm/ST elevation }\end{array}$ & $\begin{array}{l}\text { Duration } \\
\text { (month) }\end{array}$ & $\begin{array}{c}\text { Number of } \\
\text { coronary } \\
\text { vasodilators }\end{array}$ & $\begin{array}{l}\text { Number of } \\
\text { CCB }\end{array}$ & $\begin{array}{c}\text { Cause of } \\
\text { death }\end{array}$ \\
\hline 1 & 74 & M & VF & no & yes & Spontaneous Cx spasm & 11 & 2 & 2 & PEA \\
\hline 2 & 61 & M & VF & no & yes & $\mathrm{ACh}(\mathrm{R}: 50 / \mathrm{L}: 100) \# 3(\mathrm{~d}) \# 6(\mathrm{~d})$ & 15 & 1 & 1 & PEA \\
\hline 3 & 71 & M & VF & no & no & $\begin{array}{l}\mathrm{ACh}(\mathrm{L}: 50) \# 8 / 13(\mathrm{t}) \\
\# 1-3 \text { spontaneous spasm }\end{array}$ & 11 & 3 & 1 & Unknown \\
\hline Total & 68 & & & 0 & 2 & & $12.3 \pm 2.3$ & $2.0 \pm 1.0$ & $1.3 \pm 0.6$ & \\
\hline
\end{tabular}

(ICD: implantable cardioverter-defibrillator, CCB: calcium channel blocker, M: male, F: female, VF: ventricular fibrillation, PEA: pulseless electrical activity, Cx: circumflex artery, ACh: acetylcholine, R: right coronary artery, L: left coronary artery, (d): diffuse spasm, (f): focal spasm, (t): total spasm, VSA: vasospastic angina)

Ahn et al $(2.3 \pm 0.8)^{10)}$. Variant angina is one category of higher VSA disease activity. Compared with non-variant angina, cardiologists may administer abundant coronary vasodilators to suppress the angina attacks in patients with active variant angina. Variant angina is along the same lines as coronary spasm. However, A-SCD due to coronary spasm may be another special category of VSA. These patients may have a higher risk type. Cardiologists should reconsider their thought about medications in patients with A-SCD due to coronary spasm.

\section{ICDs}

Although ICDs were implanted in more than half of patients with A-SCD due to coronary spasm in this study, appropriate ICD therapies were found in just 8 patents (13.8\%). This number was lower than that reported by Sueda et al but not significant $(24.1 \%(33 / 137) \text { vs } 13.8 \%(8 / 58), p=0.1068)^{7}$. In this article, we could not find any difference about medications between patients with and without ICDs. ICD implantation is not a final therapy for patients with A-SCD due to coronary spasm. Cardiologists do not currently have a precise selection tool for ICD implantation. Decision of requiring ICD implantation in patients with A-SCD due to coronary spasm is an unsolved clinical problem.

\section{Clinical outcomes compared with other diseases except for congenital monogenetic cardiac disease after ICD implantation as a secondary prevention}

According to previous reports, $23 \%-34.4 \%$ of patients without congenital monogenetic cardiac disease died in the secondary prevention after ICD implantation, and appropriate ICD therapy was recognized in $37 \%-39.2 \%$ of these patients during median follow-up period of approximately 5 years ${ }^{12,13)}$. In our study, mortality was $3.1 \%$ during median follow-up of 27.1 months in patients with A-SCD due to coronary spasm, whereas death rate was $3.4 \%$ during median follow-up of 29.3 months in patients with A-SCD due to coronary spasm after the implantation of ICD. The frequency of appropriate ICD therapy in this study was remarkably lower than previous reports. Furthermore, the clini- cal outcomes in patients with A-SCD due to coronary spasm were satisfactory under optimal medical and mechanical treatment.

\section{Spasm provocation tests under medications}

We already reported spasm provocation tests under medications in patients with refractory VSA on emergency admission and with A-SCD due to coronary spasm ${ }^{14-18)}$. In this study, spasm provocation tests under medications were observed in 18 patients. All 18 patients were alive and had significantly large number of coronary vasodilators and CCBs. Provoked spasm attenuated or disappeared in $7(38.9 \%)$ patients, while the remaining 11 patients $(61.1 \%)$ had no attenuation of provoked spasm irrespective of spasm provocation tests under medications. In the real world, cardiologists have no method or strategy to define the real coronary spasticity or effectiveness of coronary vasodilators to suppress serious catastrophic coronary spasm. In this study, we could not prove the direct efficacy of spasm provocation tests under medications when we decided to implant an ICD in patient with A-SCD due to coronary spasm.

\section{Study limitations}

There are several limitations in this study. The first limitation is that sample size was small, and the response rate of questionnaire was $16.7 \%$ of all 204 institutions. In 2004 and 2005, we sent the questionnaire concerning the number of cases of coronary arteriography, percutaneous coronary intervention, invasive/ non-invasive spasm provocation tests, and the clinical status of coronary spasm to the members of the JCS in 120 cardiology hospitals in the Chugoku/Shikoku area and in 1,177 cardiology hospitals in all of Japan ${ }^{19-21)}$. The surveys were returned form 45 hospital (37.5\%) and 208 hospitals (17.7\%), respectively. Compared with the previous questionnaires, the collection rate in this article was not different from all Japan questionnaires. The second limitation is missing precise characteristics about coronary risk factors and serum data in this study subjects with A-SCD due to coronary artery spasm because of questionnaire flaw. The 
third limitation is also missing data about the value of left ventricular ejection fraction, side effect of ICD implantation including infection and inappropriate ICD therapies because of questionnaire flaw. Further study concerning medications and the necessity for an ICD will be necessary for characterizing A-SCD due to coronary spasm in the future.

\section{Conclusions}

Clinical outcomes in patients with A-SCD due to coronary spasm is satisfactory under medical and mechanical therapy. The incidence of death in patients with ICD was not different from those without it. Appropriate ICD therapies were observed in just $13.8 \%$ of patients, whereas the remaining $86.2 \%$ of patients had no mechanical actuations. Medications were reinforced and no death was observed in patients with spasm provocation tests under medications. Decision of requiring the ICD implantation in patients with A-SCD due to coronary spasm is an unsettled clinical problem.

\section{Appendix}

We thank the following for the cooperation.

Mitsuru Ishii, MD (Department of Cardiology, National Hospital Organization Kyoto Medical Center), Takeo Kaneko, MD (Shimonoseki City Hospital), Jun Nakajima, MD (Yokosuka Kyosai Hospital), Jun Takahashi, MD (Yokosuka Kyosai Hospital), and Hironobu Kikuchi, MD (The University of Tokyo Hospital).

\section{Sources of funding}

None.

\section{Conflicts of interest}

The authors declare that they have no conflict of interest.

\section{References}

1) Myerburg RJ, Kessler KM, Mallon SM, et al: Life-threatening ventricular arrhythmia in patients with silent myocardial ischemia due to coronary artery spasm. N Engl J Med 1992; 326: 1451-1455

2) Meisel SR, Mazur A, Chetboun I, et al: Usefulness of implantable cardioverter-defibrillator in refractory variant angina pectoris complicated by ventricular fibrillation in patients with angiographically normal coronary arteries. Am J Cariol 2002; 89: 1114-1116

3) Mitchell LB: Use of the implantable cardioverter-defibrillator in patients with coronary artery spasm as the apparent cause of spontaneous life-threatening ventricular tachycardia or ventricular fibrillation: crossing the spasm sudden death chasm. J Am Coll Cardiol 2012; 60: 914-916

4) Hendriks ML, Allaart CP, Bronzwaer JGF, et al: Recurrent ventricular fibrillation caused by coronary artery spasm leading to implantable cardioverter defibrillatior implantation. Europace 2008; 10: $1456-$ 1457
5) 2018 JCS/JHRS Guidelines on non-pharmacotherapy of cardiac arrhythmias. www.j-circ.or.jp/guideline/pdf/JCS2018 kurita nogami.pdf (2019, accessed 30 December 2019)

6) JCS joint working group: Guidelines for diagnosis and treatment of patients with vasospastic angina (Coronary Spastic Angina) (JCS 2013). Circ J 2014; 78: 2779-2801

7) Sueda S, Kohno H: Optimal medications and appropriate implantable cardioverter-defibrillator shocks in aborted sudden cardiac death due to coronary spasm. Intern Med 2018; 57: 1361-1369

8) Matsue Y, Suzuki M, Nishizaki M, et al: Clinical implications of an implantable cardioverter-defibrillator in patients with vasospastic angina and lethal ventricular arrhythmia. J Am Coll Cardiol 2012; 60: 908-913

9) Eschalier R, Souteyrand G, Jean F, et al: Should an implanted defibrillator be considered in patients with vasospastic angina? Arch Cardiovasc Dis 2014; 107: 42-47

10) Ahn JM, Lee KH, Yoo SY, et al: Prognosis of variant angina manifesting as aborted sudden cardiac death. J Am Coll Cardiol 2016; 68: 137-145

11) Mañero MR, Oloriz T, de Waroux JBP, et al: Long-term prognosis of patients with life-threatening ventricular arrhythmias induced by coronary artery spasm. Europace 2018; 20: 851-858

12) Almehmadi F, Porta-Sánchez A, Ha ACT, et al: Mortality implications of appropriate implantable cardioverter defibrillator therapy in secondary prevention patients: Contrasting mortality in primary prevention patients from a prospective population-based registry. J Am Heart Assoc 2017; 6: e006220. doi: 10.1161/JAHA.117.006220.

13) van Welsenes GH, van Rees JB, Willem Borleffs CJ, et al: Long-term follow-up of primary and secondary prevention implantable cardioverter defibrillator patients. Europace 2011; 13: 389-394

14) Sueda S, Fujimoto K, Sasaki Y, et al: Ventricular fibrillation survivor due to painless multiple spasm including left main trunk: is the subcutaneous implantable cardioverter-defibrillator necessary? J Cardiol Cases 2019; 20: 118-121

15) Sueda S, Kohno H, Miyoshi T, et al: Spasm provocation tests performed under medical therapy: A new approach for treating patients with refractory coronary spastic angina on emergency admission. Intern Med 2014; 53: 1739-1747

16) Sueda $S$, Sakaue $T$, Okura $T$ : Spasm provocation tests under medication may help decide on medical or mechanical therapy in patients with aborted sudden cardiac death due to coronary spasm. Intern Med 2020; 59: 1351-1359

17) Sueda $S$ : Optimal medical or mechanical treatment for patients with aborted sudden cardiac death due to coronary spasm. J Coron Artery Dis 2020; 26: 17-23

18) Sueda S, Miyoshi T, Sasaki Y, et al: Sequential spasm provocation tests might overcome a limitation of the standard spasm provocation tests. Coron Artery Dis 2015; 26: 490-494

19) Sueda S, Izoe $Y$, Kohno H, et al: Need for documentation of guidelines for coronary artery spasm: An investigation by questionnaire in Japan. Circ J 2005; 69: 1333-1337

20) Sueda S, Oshita A, Izoe Y, et al: Potential risk caused by the lack of recognition of coronary spasm: Analysis of the coronary spasm questionnaire in Japan. J Cardiol 2006; 49: 83-90 (Article in Japanese)

21) Sueda S, Oshita A, Izoe Y, et al: Survey of coronary spasm in Japan 
Journal of Coronary Artery Disease 2020; 26: 91-99

before the establishment of spasm guideline: Analysis of questionnaire throughout Japan. J Cardiol 2006; 48: 333-343 (Article in Japanese) 